\title{
LONG-TERM RESULTS OF PERCUTANEOUS MANAGEMENT OF LIVER HYDATID CYSTS: EXPERIENCE OF UNIVERSITY HOSPITAL IN ENDEMIC REGION
}

\author{
Y. Cherradi, R. Afifi, W. Khannoussi, M. Firwana, A. Rahaoui, M. Benazzouz, A. Essaid. \\ Department of Hepatogastroenterology "Médecine C", Ibn Sina University Hospital, Rabat, Morocco. \\ Medical School of Rabat, Mohammed Vth University, Rabat, Morocco.
}

\begin{abstract}
Background and objective: Surgery was considered for years the standard treatment for all stages of liver hydatid cysts (LHC). Percutaneous treatment has becomes a fast, reliable and more efficient method in selected cases. The purpose of this study is to evaluate the effectiveness of percutaneous treatment of LHC on the basis of our department long-term results.

Patients and methods: This study includes all patients who benefited from percutaneous treatment for LHC from December 1998 to April 2012. Puncture aspiration, injection, and re-aspiration (PAIR) were used for hydatid cysts smaller than $6 \mathrm{~cm}$. Larger cysts, infected cysts and those with biliary fistula were treated by puncture associated to drainage (PA-PD). Absolute alcohol was used as sclerosing agent. Reduction of the size of the cyst more than $50 \%$, pseudo-tumour echo pattern and disappearance of the cyst at the follow-up were retained as criteria of treatment efficacy.

Results: Two hundred thirty patients (136 female and 94 male; mean age: 35 years old) with 278 LHC underwent percutaneous treatment. Mean initial cyst diameter was $76.8 \mathrm{~mm}$ [20-180 mm]. According to Gharbi's classification, types I and II LHC accounted for $74 \%$ and $25 \%$ respectively. Fourteen patients $(6 \%)$ presented with an infected cavity and 27 patients (12\%) had a biliary fistula at diagnosis (12\%). PA-PD was initially performedin 23 patients. No mortality, abdominal dissemination, or tract seeding occurred. Minor complications like urticaria, cutaneous rash and fever were reported in 24 patients (10\%). One case of anaphylactic shock was reported with good evolution. Mean hospitalization time was 3 days \pm 1.5 for uncomplicated cases and 16.5 days \pm 4.2 for complicated cases. 229 out of 230 patients were cured, whereas one recurrence has been reported.

Conclusion: Percutaneous treatmentis efficient and safe and offers complete cure in selected patients with the advantage of short hospitalization.
\end{abstract}

KEYWORDS: Drainage, Hydatid Cyst, Liver, Percutaneous Puncture, Ultrasound (US).

\section{Corresponding Author:}

Dr. Younès Cherradi, MD.

E-mail: cherradiyounes@ hotmail.com

Adress: Mohamed $\mathrm{V}^{\text {th }}$ Hospital, Sefrou, Morocco.

Copyright $\odot$ 2012- 2016 Dr Y. Cherradi and al. This is an open access article published under Creative Commons Attribution -Non Commercial- No Derives 4.0 International Public License (CC BY-NC-ND). This license allows others to download the articles and share them with others as long as they credit you, but they can't change them in any way or use them commercially.

\section{INTRODUCTION}

Hydatid cyst in humans is caused by helminthis especially by the larval form of Echinococcus granulosus which causes development of cysts mostly in liver (60-70\%) and lungs (20-30\%) [1]. The disease may spread to almost all organs [2] and many cases reported unusual locations (heart, gallbladder, mediastinum lymph node, pancreas...) [2-5]. It's a real medical public health problem. Like other Mediterranean countries and sheepraising areas $[6,7]$, Morocco is an endemic country and management of hydatid cysts of the liver is one of primary national public health programs (Fig. 1).The prevalence has been evaluated recently and is around $1.9 \%$. (Unpublished data)

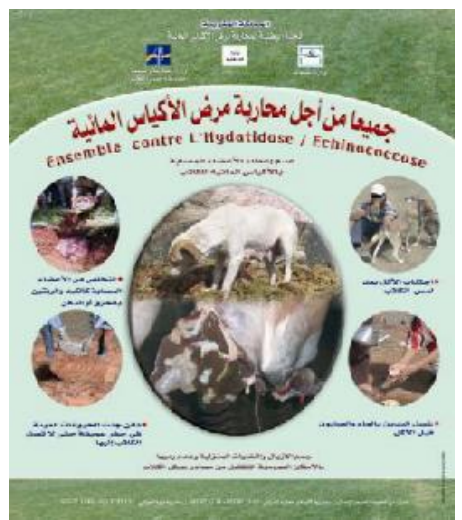

Fig. 1: Poster illustrating an aspect of the education and information campaign for general population in the national program for prevention of hydatidosis. 


\section{imoms}

Journal of Medical and Surgical Research

Ultrasonography (US) is considered as the first choice method in the diagnosis and follow-up of hydatid liver cysts. Different sonographic appearances of the disease have been described extensively [8-10]. Previously, surgery was considered as the conventional treatment of hydatid cysts and actually, it'sstill the only therapeutic modality applicable over the entire spectrum of liver hydatiddisease. However, it's known that new treatment approaches have evolved in the last three decades as alternative therapies in the management of hepatic hydatidosis [9]. In this study, we are interested in the percutaneous therapeutic approach: PAIR for puncture and and PA-PD for drainage, which involved the management of hydatid disease and which are actually preferable in "well-selected" cases. The study we conducted aims to evaluate PAIR and PA-PD approach in term ofeffectiveness, we report the long-term results of percutaneous management of 278 hydatid cysts of the liver in 230 patients treated in our Hepatology department unit.

\section{PATIENTS AND METHODS}

It's a retrospective monocentric study including all patients who underwent percutaneous treatment for LHC since December 1998 to April 2012 in our department unit.Diagnosis of LHC has been retained on the basis of morphological findings in abdominal US; medical history, clinical presentation and serological results -when performed- were collected retrospectively. Each patient had chest radiography and abdominal ultrasonography to measure initial cysts diameter and to classify lesions according to Gharbi's classification (Table I).

Table I: Gharbi's Classification.

\begin{tabular}{|c|c|}
\hline Type & US' Cyst appearance \\
\hline Type I & $\begin{array}{l}\text { Simple and monovesicular cystic lesion with } \\
\text { uniform anechoic content. (fig. 2) }\end{array}$ \\
\hline Type II & $\begin{array}{l}\text { Monovesicular cyst with Detached membrane } \\
\text { (fig. 3). }\end{array}$ \\
\hline Type III & $\begin{array}{l}\text { Multiple septa and daughter cysts on US and } \\
\text { CT. (fig.4) }\end{array}$ \\
\hline Type IV & $\begin{array}{l}\text { Rounded or irregular image with } \\
\text { heterogeneous content. (fig.5) }\end{array}$ \\
\hline Type V & $\begin{array}{l}\text { Posterior shadowing due to calcified cystic } \\
\text { wall. }\end{array}$ \\
\hline
\end{tabular}

WHO classification (Table II) was also mentioned in some patients.

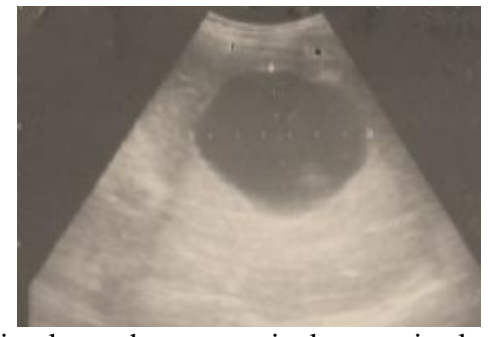

Fig.2: Simple and monovesicular cystic lesion with uniform anechoic content.

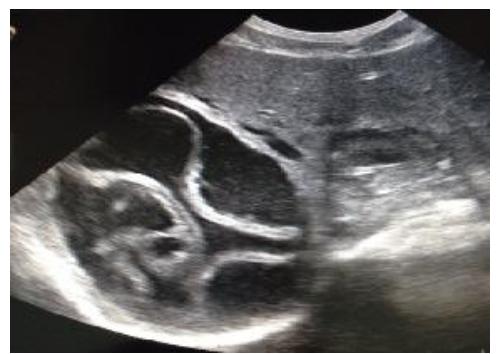

Fig.3: Monovesicular cyst with detached membrane.

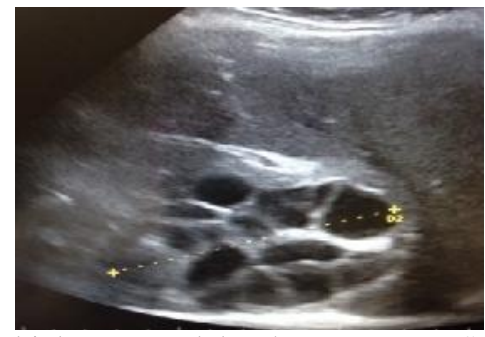

Fig.4: Multiple septa and daughter cysts on US

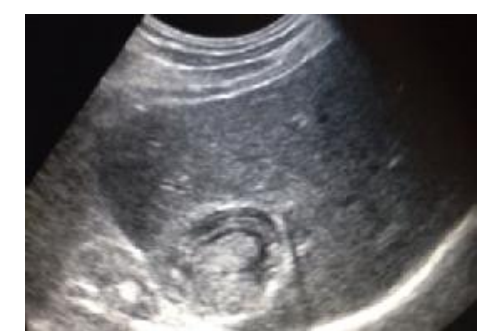

Fig.5: Rounded or irregular image with heterogeneous content.

Table II: WHO* Classification [11, 12]

CL Unilocular anechoic cystic lesion without any internal echoes and septations.

CE 1 Uniformly anechoic cyst with fine echoes settled in it representing hydatid sand

CE 2 Multiple, or multi loculated cysts. May appear honeycomb like with daughter cysts. This is a transitional stage.

CE 3 Unilocular cyst with daughter cysts with detached laminated membranes appearing as water lily sign.

CE 4 Mixed hypo and hyperechoic contents with absent daughter cysts, these contents give an appearance of ball of wool sign indicating the degenerative nature of the cyst

CE 5 Arch-like thick partially or completely calcified wall. This stage of cyst is inactive and infertile.

*WHO: World Health Organization. 
Patients previously treated by surgery or having extra-hepatic locations were not excluded. Patients with overt biliary fistulas (ruptured hydatid cysts into intra-hepatic bile ducts) were not considered for this study. Puncture, aspiration, injection, and re-aspiration (PAIR) was used for hydatid cysts smaller than $6 \mathrm{~cm}$. It was indicated in type I and type II. Type III lesions with less than three vesicles were considered for PAIR when patients were not suitable for surgery. Larger cysts, complicated cysts (infected, biliary fistula) were treated by percutaneous drainage with an indwelling catheter within the cyst cavity. The procedure protocol was the same for all patients. Cysts were punctured by a 20-gauge needle and percutaneous treatment was performed under aseptic conditions with continuous sonographic guidance and intensive monitoring to treat any complication. After initial withdrawal of cyst content, a volume of absolute alcohol approximately equivalent to one third of the amount aspirated- was injected into the cavity and then reaspirated after 20 to 30 minutes. Absolute alcohol was the only cytotoxic and sclerosing agent used. No injection was made in case of suspected covert biliary fistula. It's important to mention that, according to our unit clinical practice, the patients were not premedicated. They were observed for 24 hours after achieving the procedure. Only a Prophylactic albendazole at $10 \mathrm{mg} / \mathrm{kg}$ was started 12 hours before the puncture and then continued for one month with control of aminotransferases and neutrophils. Follow-up was based on sonography; it was performed monthly in the first 3-months period, and then twice a year for the next 5 years and once a year thereafter. Reduction of the size of the treated cyst more than 50\%and pseudo-tumour echo pattern (cyst cavity completely obliterated by echogenic material) was retained as criteria of treatment efficacy.Patients with less than five years of regular follow-up were excluded. Long-term treatment efficacy was the major endpoint of this study.

\section{RESULTS}

Two hundred seventy eightLHC in 230 patients were percutaneously treated. Mean age was 36 years old [13-60]. Female gender was prominent $(59 \% ; \mathrm{n}=136) \quad($ Sex-ratio $=0.6 \quad(94 \mathrm{male} / 136$ female)).Of the cysts, $59 \%$ were located in the right liver, $30 \%$ in the left liver and $11 \%$ had bilateral location. Thirty eight patients had been operated previously for LHC and were admitted for recurrence. Mean initial cyst diameter was $76.8 \mathrm{~mm}$ [20-180 mm]. According to Gharbi's classification, types I and II LHC accounted for $74 \%$ and $25 \%$ respectively. Fourteen patients $(6 \%)$ presented with an infected cavity and 27 patients (12\%) had a biliary fistula at diagnosis (12\%). PA-PD was initially performed in 23 patients. No mortality, abdominal dissemination, or tract seeding occurred. Minor complications like urticaria, cutaneous rash and fever were reported in 24 patients (10\%). One case of anaphylactic shock was reported with good evolution. Mean hospitalization time was 3 days \pm 1.5 for uncomplicated cases and 16.5 days \pm 4.2 for complicated cases (infection, biliary fistulae). At follow-up, repeated sonographic examinations revealed a progressive decrease in cyst size and alteration in cyst appearance. The average time for solidification was 19 months. It was obtained in $97.3 \%$ of patients. 229 of 230 patients were cured, whereas one recurrence was observed after two years and was successfully treated by PAIR (Table. III). 


\section{Mnomss}

Journal of Medical and Surgical Research

long term series results, only one recurrence $(0.99 \%)$ was reported within ten years' follow-up, which confirms the efficacy of absolute alcohol as sclerosing agent and the effectiveness of the procedure. The delay before re-aspiration of the fluid from the cavity varies from 5 to 30 minutes after injection according to each team's protocol [18]. Giorgio and colleagues opted for not reaspirating the scolicidal agent $[18,19]$.

It's important to confirm the absence of biliary fistula before injecting the sclerosing agent because of the risk of developing sclerosing cholangitis. Few cases have been reported in literature [15]; it's recommended to consider the aspect of aspired liquid and to dose bilirubin rates before the injection of the scolicidal agent to prevent such complication. No secondary sclerosing cholangitis was reported in our series.

In our clinical practice, PAIR is performed in type I and type II hydatid cysts according to Gharbi's classification. Type III cysts with less than three vesicles could be also treated by PAIR. Some authors performed successfully PAIRprocedure with prolonged catheterization and multiple alcohol injections in a multi-vesiculated cyst without solid matrix (WHO type CE2 cysts) in a patient not suitable for surgery [20]. This seems to be controversial, Giorgioand al. and Kabaalioglu and al. reported repeated failures of PAIR in multivesiculated cysts (CE2 and CE3B) [21]. These results prompted most physicians to recommend PAIR only for monolocular cysts, with or without detached endocysts [21].Surgery continues to be the gold standard for type III LHC. For larger cysts, infected cavities and cysts with connection to biliary tree (fistulae), it's recommended an initial drainage with an indwelling catheter within the cyst cavity until daily drainage ceases. In case of intrabiliary rupture of hydatid cyst, surgical management of biliary fistula is associated with high morbidity and mortality [18]; the endoscopic sphincterotomy could be performed as a therapeutic method. The extraction of hydatid material could be performed by balloon or Dormia basket, stenting, or nasobiliary drainage [18]. PAIR is contraindicated in patients less than 3 old years and cannot be practiced in an uncooperative patient [9]. It's also contraindicated in cysts that are inaccessible to puncture or in peripheral ones that do not have a sufficient layer of hepatic parenchyma that permits trans-hepatic approach.

A major rule should be highlighted. In all cases, approaching the cyst must be through the liver parenchyma in order to minimize the possibility of cyst rupture, abdominal dissemination and anaphylactic shock (Fig.6).

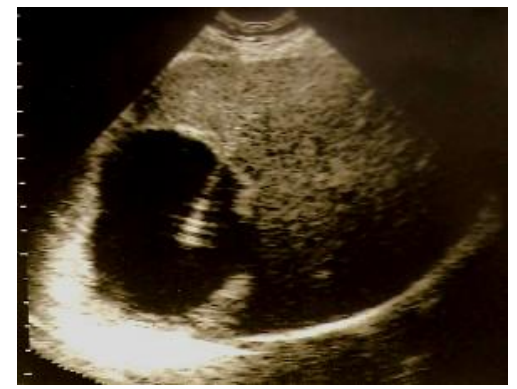

Fig.6: PAIR procedure under continuous US control: approaching the cyst must be through the liver parenchyma in order to minimize the possibility of cyst rupture, abdominal dissemination and anaphylactic shock.

Puncture is not recommended in superficial cysts. In our series, the approach seems very efficient: on 280 treated patients, only three cases of anaphylactic shock were reported without mortality or abdominal dissemination or tract seeding. The anaphylactic shock is the major and severe complication. In case of shock symptoms, the procedure should be stopped immediately with a strict surveillance in Intensive Care Unit. Major complications (anaphylactic shock, secondary echinococcosis and chemical cholangitis) are reported to be only $0.38 \%$ and secondary echinococcosis as a result of spillage of fluid is about $1.27 \%$ [15].

After percutaneous treatment, the decrease in the diameter of the cyst, the solidification of its content and the irregularity in the walls of cysts are the signs suggestive of effectiveness [8] (Fig.7).

It's important to mention that the physician should be familiar with the post-PAIR follow-up sonographic findings to prevent misinterpretation of the hypoechoic, anechoic, or hyperechoic appearance of treated cysts as recurrence [8]. Such misinterpretation may conclude wrongly to reducing the procedure's effectiveness rates. In our study, one case of recurrence has been reported. 


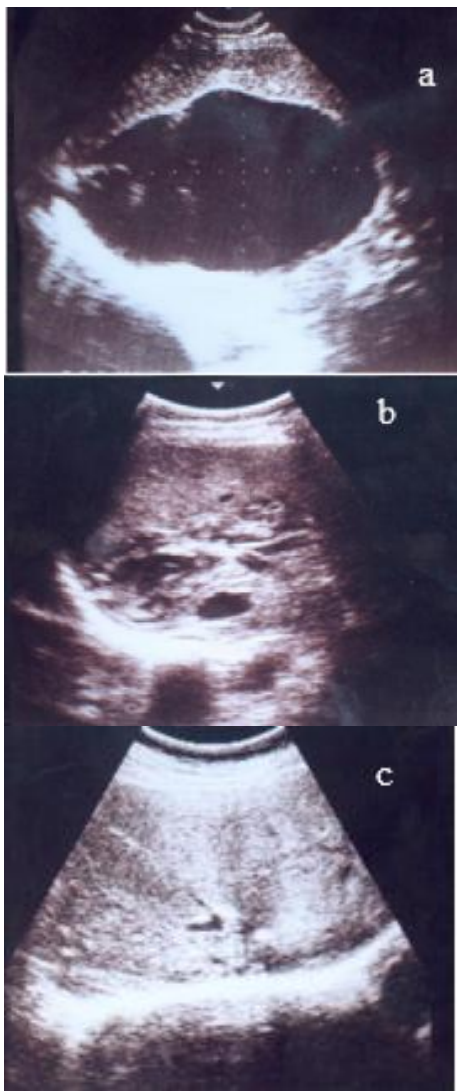

Fig.7: (a)Hydatid cyst appearance before percutaneous treatment, (b) 21 days later and (c) after 14 months of follow-up.

Nowadays, it's clearly established that percutaneous treatment for "well selected" cases is safest than surgery. Literature data report surgical mortality ranging between $0 \%$ and $6.5 \%$ [7]. LHC postoperative mortality can reach at $9.2 \%$ in radical surgery [7]. The mean hospitalisation period is 14 days in uncomplicated cases and 30 days for complicated ones [22]. Somego meta-analysis of 21 studies compared 769 patients percutaneously treated to 952 operated patients and concludes to superiority of PAIR in management of hydatid cyst [23]. PAIR in conjunction with peri-interventional albendazole/benzimidazole was more effective than surgery and was associated with lower rates of morbidity and mortality, decreased recurrence risk and a shorter hospital stay [24]. Khuroo and al found PAIR associated to benzimidazole derivatives to be as effective as open surgical drainage with fewer complications and reduced cost [15]. In a single-center experience from Turkey, Yagci and al compared surgery, laparoscopic surgery, and percutaneous approaches in 355 patients treated for LHCs over a period of 10 years and concluded that PAIR is an effective and safe option [25].

\section{CONCLUSION}

Our long-term follow up results indicate that percutaneous management of LHC is efficient, safe and reliable method. It offers complete cure in "well-selected" cases with significant low morbidity and mortality rates. It must be considered as the treatment of choice when indications are selectively retained and the knowledge and the experience of percutaneous approach are provided.

\section{REFERENCES}

1. Menzes da silva A, Hydatid cyst of the liver- criteria for the selection of appropriate treatment, ActaTropica, 85 (2003), 237-242.

2. SevinçHallaçKeser, Ayşegül Selek, DilekEce, CemCahit Barişik, SibelŞensu, GoncaGülGeçmen and al. Review of Hydatid Cyst with Focus on Cases with Unusual Locations. DOI: 10.5146/tjpath.2016.01369

3. Gómez R, Allaoua Y, Colmenares R, Gil S, Roquero $P$ and M Ramia J. Hydatid cyst of the gallbaldder: A systematic review of the literature. World J Hepatol. 2016 Sep 8; 8(25): 1087-1092 DOI: $10.4254 /$ wjh.v8.i25.1087

4. Ouadnouni Y, Lakranbi M and Smahi M. "Mediastinum Lymph Node Hydatidosis." Journal of Medical and Surgical Research 2014; 1 (1): 28.

5. El Sorogy M, El-Hemaly $M$ and Aboelenen A. Pancreatic body hydatid cyst: A case report. Int $\mathrm{J}$ Surg Case Rep. 2015; 6: 68-70.

6. Duta C, Lazar C, Bordos D. Percutaneous treatment of the liver hydatid cysts, TMJ 2004, 54 (4).

7. El Malki H.O, Souadka A, Serji B, Benkabbou A, Mohsine R, Ifrine L, Belkouchi A. Radical Surgery for Liver Hydatid Cyst. Journal of Medical and Surgical Research (JMSR) 2014; 1(2) 2014: 30- 36.

8. Turgut AT1, Akhan O, Bhatt S, Dogra VS. Sonographic spectrum of hydatid disease. Ultrasound Q. 2008 Mar; 24(1):17-29.

9. Pedrosa I, Saíz A, Arrazola J, Ferreirós J, and S. Pedrosa C. Hydatid Disease: Radiologic and Pathologic Features and Complications. RadioGraphics 2000; 20(3): 795-817

10. http://apps.who.int/iris/bitstream/10665/67207/1/W HO_CDS_CSR_APH_2001.6.pdf

11. Derbel F, Ben Mabrouk M, Ben HadjHamida M, Mazhoud J, Youssef S, Ben Ali A and al. Hydatid Cysts of the Liver - Diagnosis, Complications and Treatment. Abdominal Surgery 105- 138.

12. Radiopedia. org https:// radiopaedia.org/ articles/world-health-organization-2001classification-of-hepatic-hydatid-cysts

13. Corona M, Cannavale A, Bruni A, Boatta E, Allegritti M, Lucatelli Pand al. Case report: Percutaneous treatment of multiple honeycomb-like liver hydatid cysts (type III CE2, according to WHO classification). Indian J Radiol Imaging. 2012 JanMar; 22(1): 23-26. 
14. M. Benazzouz and E. A. Essaid.Traitement percutané du kyste hydatique du foie, Encycl. Med Chir 2004 (Paris France) - Hépatologie ;1 (4) : 131137.

15. AnandS, S. Rajagopalan B, Mohan R. Management of liver hydatid cysts e Current perspectives. Medical Journal Armed Forces India 68 (2012) 304 309

16. Borahma M, Afifi R, Benelbarhdadi I, Ajana FZ, Essamri W, Essaid A. Endoscopic retrograde cholangiopancreatography in ruptured liver hydatid cyst. Indian J Gastroenterol. 2015 Jul; 34 (4):330-4.

17. Benkabbou A, Afifi R, Soudaka A. Tailored approach to cystic liver hydatidosis is mandatory. Surgery 2016 September; 160 (3): 819- 820.

18. Fìlice C, Brunetti E, R Bruno E, G Crippa F. Percutaneous drainage of echinococcal cysts (PAIR-puncture, aspiration, injection, reaspiration): results of a worldwide survey for assessment of its safety and efficacy. Gut 2000;47:156-157

19. Giorgio A, Tarantino L, Francica G

and al. (1992) Unilocular hydatid liver cysts: treatment with US-guided, double percutaneous aspiration and alcohol injection. Radiology184:705-710.
20. Corona M, Cannavale A, Bruni A, Boatta E, Allegritti M, LucatelliP and all.Indian J Radiol Imaging. 2012 Jan-Mar; 22(1): 23-26. Case report: Percutaneous treatment of multiple honeycomb-like liver hydatid cysts (type III CE2, according to WHO classification) DOI: 10.4103/0971-3026.95399

21. Junghanss T, da Silva AM, Horton J, Chiodini PL, Brunetti E. Clinical Management of Cystic Echinococcosis: State of the Art, Problems, and PerspectivesAm. J. Trop. Med. Hyg., 79(3), 2008, pp. 301-311.

22. Zeljko. B, Bosanac Ljubomir Lisanin, Percutaneous drainage of hydatid cysts in the liver as a Primary Treatment: Review of 52 Consecutive Cases with Long-term Follow up. Clinical Radiology (2000) 55, 839-848.

23. Smego RA, Bhatti S, Khaliq AA, Beg MA. Percutaneous aspiration-injection-reaspiration drainage plus albendazole or mebendazole for hepaticcysticechinococcosis: a meta-analysis. Clin Infect Dis.2003; 37: 1073-1083.

24. iGavara G, López-Andújar R, Belda Ibáñez T, José M RamiaÁngel, Moya Herraiz A, Orbis F Castellanos, and all. Review of the treatment of liver hydatid cysts, World J Gastroenterol. 2015 Jan 7; 21(1): 124-131.

25. Yagci G, Ustunsoz B, Kaymakcioglu N, Bozlar U, Gorgulu S, Simsek A and all.Results of surgical, laparoscopic, and percutaneous treatment for hydatid disease of the liver: 10 years experience with 355 patients.World J Surg. 2005 Dec; 29 (12):1670-9. 